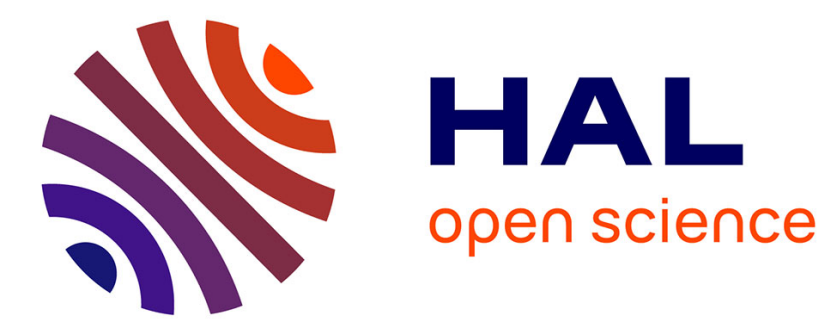

\title{
SUPERCONDUCTIVITY AND PERCOLATION IN Al-Ge FILMS
}

G. Deutscher, M. Rappaport

\section{To cite this version:}

G. Deutscher, M. Rappaport. SUPERCONDUCTIVITY AND PERCOLATION IN Al-Ge FILMS. Journal de Physique Colloques, 1978, 39 (C6), pp.C6-581-C6-582. 10.1051/jphyscol:19786262 . jpa00217699

\section{HAL Id: jpa-00217699 https://hal.science/jpa-00217699}

Submitted on 1 Jan 1978

HAL is a multi-disciplinary open access archive for the deposit and dissemination of scientific research documents, whether they are published or not. The documents may come from teaching and research institutions in France or abroad, or from public or private research centers.
L'archive ouverte pluridisciplinaire HAL, est destinée au dépôt et à la diffusion de documents scientifiques de niveau recherche, publiés ou non, émanant des établissements d'enseignement et de recherche français ou étrangers, des laboratoires publics ou privés. 
SUPERCONDUCTIVITY AND PERCOLATION IN $A_{1}-G_{e}$ FILMS *

G.Deutscher and M.L. Rappaport

Dept.of Physics and Astronomy, Tel-Aviv University, Ramat-Aviv, Israël

Résumé.- On a observé une double transition supraconductrice dans des films minces A1-Ge obtenus par coévaporation. Cette double transition est observée dans la transition résistive en fonction de la température et dans la caractéristique courant-tension. Une interprétation des résultats est proposée en termes de la théorie de percolation.

Abstract.- A double superconducting transition in co-evaporated A1-Ge films can be observed in both their resistance-temperature and current-voltage characteristics. An explanation is offered in terms of percolation theory.

Co-evaporated or co-sputtered metal-insulator mixtures are normaliy found to be in the form of metallic grains imbedded in an insulating matrix /1/ The size and shape of the grains depend on the metallic volume concentration, $x$, the rate of deposition, and the substrate temperature $/ 2 /$.

If a single, isolated grain is large enough $/ 3 /$ to have a superconducting transition at $T_{c o} / 4 /$, then mixtures with $\mathrm{x}<\mathrm{x}_{\mathrm{c}}$ would be expected to have a double superconducting transition : an incomplete transition at $T_{c o}$ and a second transition at $T_{c j}$ $<\mathrm{T}_{\text {co }}$ due to Josephson tunnelling between the grains which makes the whole sample superconducting. $x_{c}$ is the "critical" concentration for which the grains are no longer in metallic contact.

$T_{c j}$ will be less than $T_{c o}$ when the Josephson coupling energy $n k I_{c}(0) / 2 e$ of a grain to its n nearest neighbors, where $I_{c}(0)$ is the $T=0$ critical current of one such isolated junction, is less than $\mathrm{kT}_{\text {co }}$.

We have observed such a double transition in Al-Ge films with $x^{2} 0.64$. The films were prepared by coevaporation from two electron-beam guns onto room temperature glass slides at a combined rate of $\sim 50 \mathrm{~A} / \mathrm{s}$. The deposition rate of each material was independently controlled by feedback from a separate quartz crystal thickness monitor which was previous1y calibrated by interferometry . Each slide contained nine samples with concentrations differing by $\uparrow 2 \%$ due to their differing distances from the two sources. Electron microscope examination of similar concentrations evaporated onto sio showed Al

\# This research was supported in part by the U.S. Navy, contract No. HE-77-1. spheres of very uniform diameter $\sim 200 \AA$ in a nearly random close-packed structure $/ 5,6 /$.

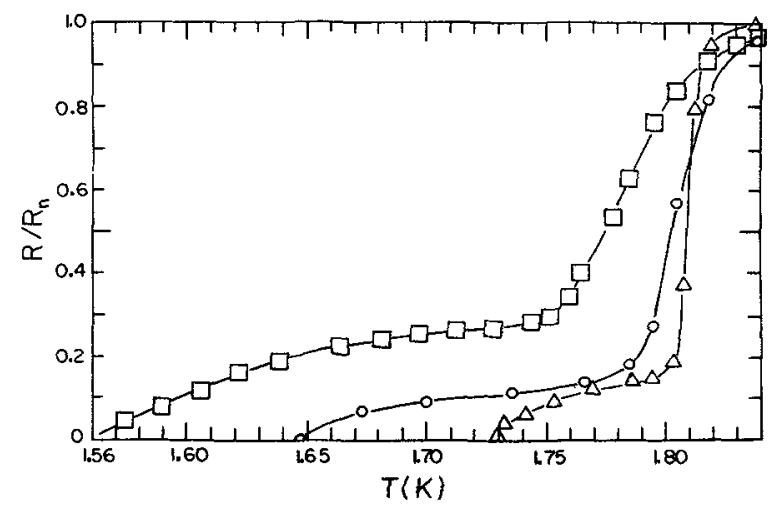

Fig. 1 : Normalized resistance vs.temperature of three samples from one slide. $\square, p_{n}=2.0 \times 10-{ }^{4} \mu \Omega-\mathrm{cm}$, $\mathrm{x}=0.65 ; 0, \rho_{\mathrm{n}}=3.0 \times 10^{3} \mu \Omega-\mathrm{cm}, \mathrm{x}=0.68 ; \Delta, \rho_{\mathrm{n}}=1.6 \times 10^{3}$ $\mu \Omega-\mathrm{cm}, \mathrm{x}=0.74$

Figure 1 shows the normalized resistance as a function of temperature for three samples from one slide. The double transition is clearly seen. As expected, $\mathrm{T}_{c o}$ is nearly independent of $\mathrm{x}$ while $T_{c j}$ decreases with increasing Ge concentration (decreasing $x$ )

Figure 2 shows the current-voltage characteristic of one sample from the same slide as in figure 1. Two main transitions are again apparent. However, the fact that the resistance falls to less than $30 \%$ of $i$ ts value at $T_{c o}$ indicates that this first transition is not due to isolated grains alone. The resistivity of these samples is greater than $10^{3} \mu \Omega-\mathrm{cm}$, so the contribution of the resistance of the grains is almost negligible. 

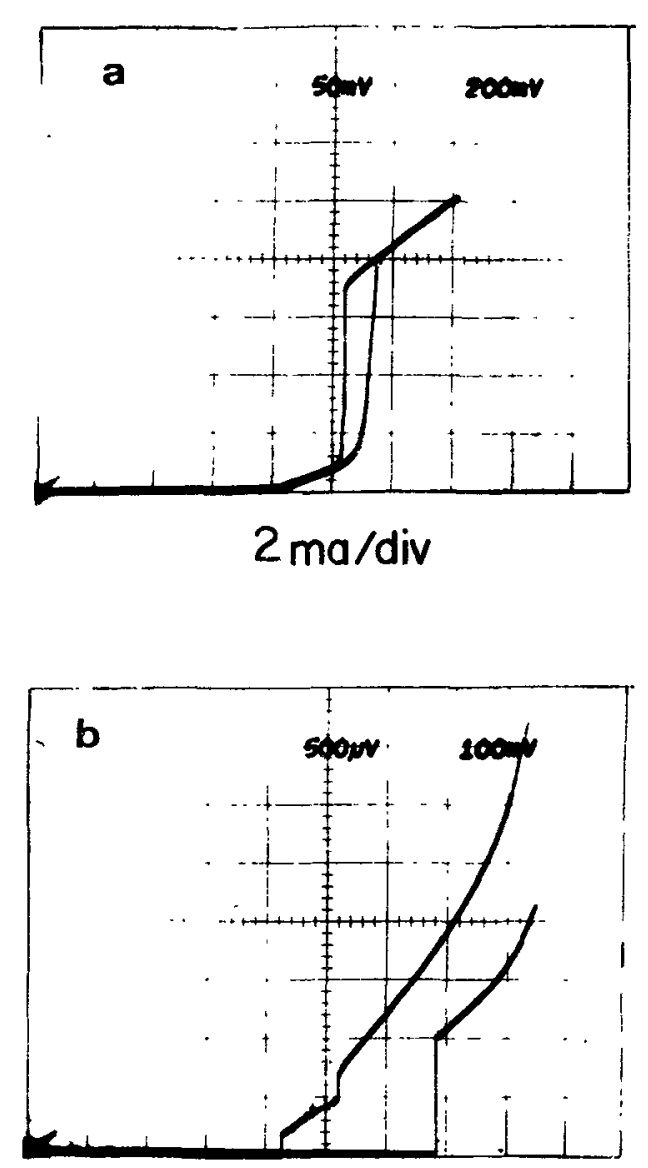

I ma/div

Fig. 2 : Current-voltage characteristic at $\mathrm{T}=1.52 \mathrm{~K}$ for a sample with $\mathrm{x}=0.78$ from the same slide as the samples in figure 1 .

a) complete characteristic with final slope equal to $R_{n}$.

b) Increased current and voltage sensitivity showing the Josephson transition.

We therefore conclude that the transition at $\mathrm{T}_{\mathrm{co}}$ includes a significant number of strongly coupled junctions as we11. These superconducting clusters then "short out" a large percentage of the sample. What percentage of the volume must be contained by these clusters before they will interconnect and short out the whole sample is one of the principle questions of percolation theory $/ 7 /$.

If we assume that the strongly coupled junctions are randomly distributed throughout the samples, then the answer is $15 \% / 8 /$. That the whole volume of the sample is not superconducting at $T_{c j}$ is supported by measurements of the critical current density below $\mathrm{T}_{\mathrm{cj}} / 9 /$. They show a much stronger dependence on temperature than is compatible with that of identical Josephon junctions, thus indicating that even below $T_{c j}$ more junctions become superconducting as $T$ decreases.

If the data near $\mathrm{T}_{c j}$ from figure 1 is replotted on $\log -\log$ paper, it is found that the resistance obeys a power law dependence $R^{\alpha}\left(T-T_{c j}\right)^{t}$ with $t=0.7$. Straley has recently shown by a percolationtype calculation that the resistance of a superconductor-normal conductor mixture below the percolation threshold for the superconductor also obeys a power law $R \propto\left(x_{c}-x\right)^{t}$ with $t=0.7$.

We therefore propose that A1-Ge mixtures with Al concentrations near $x_{c}$ and below $T_{c o}$ behave as percolation systems whose concentration of superconductor may be varied by both $\mathrm{x}$ and $\mathrm{T}$.

\section{References}

/1/ Abeles, B.et a1. Adv.Phys.24 (1975) 407

/2/ Fontaine,A. and Meunier,F., Phys.Kondens.Materie 14 (1972) 119.

/3/ Deutscher,G., Phys. Lett. 35A (1971) 28

$14 / \mathrm{T}_{\mathrm{co}}$ may be larger than the bulk $\mathrm{T}_{\mathrm{c}}$ of the super conductor because of the grains' large surface to volume ratio. See, for example, Deutscher,G. et al., J.Vac.Sci.Techno1. 10 (1973) 697

15/ Deutscher,G.,Rappaport,M.I. and Ovadyanu,2., to be published.

/6/ It is noted that $x$ for random close-packed spheres of uniform ${ }^{c}$ diameter should equal its packing fraction $f=63.8 \%$. See Finney,J.L., J.Physique 36 (1975) C2-1.

17/ Shante,V.K.S. and Kirkpatrick, S.,Adv.Phys.20 (1971) 325 and Kirkpatrick,S., Rev.Mod.Phys. 45 (1973) 574 .

/8/ Scher,H. and Zallen,R.J., Chem.Phys. 53 (1970) 3759

19/ Deutscher,G. and Rappaport,M. to be published.

/10/ Straley,J.P., Phys. Rev. 15B (1977) 5733 